\title{
YOUNG TURKS, OLD GUARDSMEN, AND THE CONUNDRUM OF THE BROKEN MOLD: A Progress Report on Twenty Years of Information Systems Research
}

\author{
Bonnie Kaplan \\ Yale University \\ Duane P. Truex III \\ Florida International University and \\ Georgia State University \\ David Wastell \\ School of Informatics \\ University of Manchester

\begin{abstract}
A. Trevor Wood-Harper
School of Informatics, University of Manchester, and School of Accounting and Information Systems,

University of South Australia
\end{abstract}

\section{INTRODUCTION}

It is now 20 years since the first Manchester conference on information systems research methodology. Since that auspicious gathering, the reputation, the reach, and the impact of the IFIP WG 8.2 scholarly community has extended into mainstream IS journals, conferences, and academic institutions world-wide. Twenty working conferences in eight nations have published almost 400 papers covering all manner of social theories and IS topics. The first gathering had bold and radical ambitions. Its provocative title, "Information Systems Research-A Doubtful Science?," challenged the prevailing orthodoxy that the research methods of "normal science" should be the only methods defining proper research in our field. The gauntlet was thrown and the research 
methods theme, albeit with evolving twists, was revisited again at the 1990 Copenhagen IFIP 8.2 Working Conference, and again in 1997 in Philadelphia. The Copenhagen gathering was organized around the assumption that radically different research approaches existed in the IS research community; the call was made for methodological pluralism and the debate extended around the philosophical traditions grounding IS research methods.

The Philadelphia conference organizers acknowledged the battle for recognition fought in the previous decade by IS researchers deploying nontraditional research methods, and that these approaches were finally being recognized. They argued that mature disciplines allowed both qualitative and quantitative research traditions to coexist. In contrast to the more tentative position of the earlier conclaves, the Philadelphia conference invited authors to "assertively and unapologetically" apply and refine qualitative research approaches. Where the Copenhagen conference called for methodological pluralism, Philadelphia dealt more with the diversity in approaches within the qualitative research community. Each of the conferences took into account the role of previous research methods conferences in shaping the debate, and each was a product of the larger disciplinary discourse about research and the evolution of the discipline.

Following in this tradition, and 20 years after the first WG 8.2 research methods conference, we thought it timely to look back and take stock of the working group's impact upon the practice of information systems development (ISD) and use in organizations and other social contexts. This conference is the result. We variously wondered: How relevant has our work really been? To what extent have we made an impact on IS practice? To what degree have our theories been enhanced by drawing on practice? Has the positivist mold really been broken or is the victory pyrrhic? How has the past informed our developing and future research approaches?

We invited researchers and practitioners, both members of the now "old guard" and the new "young Turks," to continue WG 8.2's tradition of debating method, exploring the relevance of our research, and examining interrelationships between information systems, organization, and society. We solicited both empirical and theoretical papers that examined or empirically used IS research methods. The return of the conference to its geographical origin provided an auspicious opportunity both to celebrate the iconoclastic idealism of its forebears and to take stock of how the discourse on research questions, themes, and methods has evolved in the interim. We were delighted with the response to the Call for Papers, with a record number of submissions being received. As noted in the Preface, a final selection of 33 full research papers was made, together with 6 panels and a novel category of short position papers.

The remainder of this chapter provides an overview of these various submissions, beginning with the full research papers. These have been clustered into a number of themes, which are reflected in the broad structure of the conference program. The first section contains the three invited papers, which attempt in their various ways to outline a set a panoramic views of our field, challenging the community to look critically at our prescriptions, practices, and rhetoric. The further groupings of papers reflect a diverse response to the various imperatives of this agenda. Section 2 contains papers addressing foundational issues bearing on the core identity of the field itself, whereas those in the subsequent section exemplify the critical interpretive tradition that has come to flourish within the field, emblematizing (perhaps) our success in challenging the research 
orthodoxy of two decades ago. This is followed in section 4 by a clutch of papers on another alternative to the paradigm of normal science, namely action research, which has gained a strong following within the field. A concern with the use of social theory within IS research is the characteristic that unites the papers in section 5; these papers emphasize new developments in theory, either of an integrative nature or regarding the potential of some relatively unused, but possibly fruitful, new approach. The papers in section 6 focus on the second sense of method which preoccupies us within our field (i.e., the process for building systems rather than for conducting research). Methodological issues regarding information systems development, and the problems that beset IS projects in real organizational contexts, reflect the linked concerns of these papers. Following this overview of the research papers, we give a brief overview of the panels and position papers, then move on in our final remarks to the adumbration of crosscutting themes and issues that emerge when reflecting on the conference content as a whole.

\section{OVERVIEW OF THE PAPERS AND OTHER SUBMISSIONS}

\subsection{Panoramas}

The invited papers open the book, laying out panoramic views and consequent challenges of the field. In the opening paper, Lee makes an attempt to collectively hoist us by our own petard. The expression means to be thrown up in the air by an explosive charge (the petard) placed under castle walls to gain access. The WG 8.2 community has been storming the castle gates since its earliest days, with its methods conferences at the vanguard of the campaign. Lee's paper challenges us to apply some of our own prescriptive medicine to the conduct of our research. Using three articles from the previous WG 8.2 methods conferences, Lee uses the rhetorical ploy of replacing key phrases such as "information systems development" with "IS research" or "research on the practice of research" to test the fit of our own prescriptions on our process of making research. Lee imagines a gathering of influential IS researchers to design "helpful interventions into our own research community," employing our prescriptions for others to our own process of research production and community building. The gathering would examine the process by which we, through our journal editing activities and tenure and promotion decisions, come to decide that which is enduring and of high quality. Lee challenges us to turn our lenses of analyses on our own community of practice.

In the second paper, Sawyer and Crowston survey all of the previous WG 8.2 proceedings. They identify six characteristic research themes: (1) an orientation toward social theories, (2) dominant conceptualizations of information and technology and a common level of analysis, (3) an orientation toward the use of intensive research methods, (4) use of critical and analytical perspectives in research, (5) an openness to a range of research settings, and (6) an open discourse on the study of IS in organizations and society. They argue that WG 8.2 has not been as influential as it might have been in shaping the wider disciplinary discourse, and offer ideas how it might be more influential in the future. They see two opportunities to capitalize on current strengths 
and past traditions: by better conceptualizing information and communication technologies (ICT) and by leading in further developing socio-technical theories of IS. They illustrate how future 8.2 scholars may resolve dualistic tendencies and understand ICTs as simultaneously social and technological.

In the third paper, Boland and Lyytinen recall how previous WG 8.2 methods conferences were "characterized by our fervent struggles to define the correct way of doing research," lamenting that despite the progress made, "we now find ourselves in another quagmire, rooted in a questioning of our identity." Boland and Lyytinen rise to Lee's challenge in their analysis of the Group's identity "as found in our theories, our method and our reflexive practices," and also to the concerns of Sawyer and Crowston in suggesting the design of a better interface of the socio-technical world we as IS scholars inhabit. Boland and Lyytinen argue against the current and misguided predilection of defining the core of our field by what objects we study and how we align ourselves with "the things that should be part of our identity." They propose instead that we consider the process through which we construct a common identity, and that we consider researchers as designers of a process and of a shared identity. To illustrate the point, they apply a kind of structurational analysis reflexively to their own research.

\subsection{Reflections on the IS Discipline}

This section picks up themes of reflexivity, challenge, and identity. These papers are distinguished by discussion of crises and dichotomies within IS as a discipline. Ramage begins by challenging us with profound questions of IS identity and institutional acceptance in an engagingly playful way. His analysis provides, in the words of Marcon et al., "an altered frame of mind" as he argues for a model of information systems in terms of cyborgs, a metaphor for the human-technical mix of our times, and a description of situations where the social and the technical merge and blur. IS, he reminds us, is inevitably interdisciplinary, straddling the divide between social and technical perspectives. Ramage embraces the inherent nature of IS as cyborg formed by an unholy fusion of many disciplines, facing continual struggle for self-identity and legitimization: "to live as a cyborg is not to be comfortable, it is to be challenging and challenged." His discussion suggests an explanation for the continual IS crises: Cyborgs are threatening. Whether individual researchers or entire disciplines, cyborgs break societal norms. The very existence of the cyborg breaks down power achieved and maintained through categorization and dichotomization. Cyborgs are seen as double-headed monsters, to be persecuted or rendered invisible.

Rowe, Truex, and Kvasny also address the constant challenge to the credibility of IS as an academic field, calling for an end to the cognitive legitimacy crisis on political, economic, and scholarly grounds. Their concern is with establishing clear boundaries between our research concerns and those of others, so as to "mark a territory that is uniquely our own." They argue that our focus on evaluation and control are the distinctive characteristics of IS that differentiate us from other fields. They ask what we mean by an IT-enabled solution and even by information system while noting that ontology, too, has multiple, and therefore unclear, definitions in our field. They invoke three French sociologists (Crozier, Bourdieu, and Latour) to focus debate on the 
ontological grounding of our field, thus highlighting the contribution of French scholars and encouraging us to continue to explore the relevance of their work.

Ramage pushes us to reject either/or language in favor of both/and, thus avoiding entrapment in a single understanding that works only for a particular time. The same might be said for other dichotomies within IS, including rigor/relevance, qualitative/ quantitative, and theory/practice. Introna and Whittaker look at these divides, raising the question of power while tracing the shift away from practice in MIS Quarterly. Taking a Foucauldian stance, they analyze editorial statements and other claims to tackle the important question of what the politics of truth means for research and publishing in academicjournals. Their analysis traces growing tension between research and practice, or relevance and rigor, as MIS Quarterly pursued a policy of raising its stature as an academic journal. Methodological emphasis also shifted, with editorial calls for positivistic and theory-driven papers followed by attempts to make the journal more pluralistic. Under the current leadership, MIS Quarterly claims to have moved beyond "methods wars" and dismissed methodology as a problem. Nevertheless, the strong emphasis on empirical work makes it difficult for critical and speculative papers to get an audience in MIS Quarterly. Consequently, Introna and Whittaker argue that journal publication is more an indication of compliance with a journal's regime of truth than an indication of quality, and urge a questioning attitude toward attempts to institutionalize rankings of journals.

Jones also rises to the role of intellectual inquisitor by examining publication practice in the light of publication theory. He compares the doxa of a generally accepted set of required elements for good IS research against what actually is done in practice. He tests a set of papers judged to be best of breed in our field, finding that we do not practice what we preach. He posits four accepted principles: that good research should follow the scientific method, should fulfill certain criteria, should be relevant, and should employ multiple methods. His analysis of the best papers from the International Conference on Information Systems and MIS Quarterly either illustrates a kind of "do as we say and not as we do" hypocrisy in both the positivistic and the interpretive communities, or that something more complicated constitutes good research. This suggests that methodological checklists "may be more likely to encourage ritualistic adherence than improved [research] practice." Thus Jones invites us to conduct a kind of methodological reality check much like that envisioned by Lee.

The remaining authors in this section attempt to resolve splits within the discipline. Marcon, Chiasson and Gopal also attempt to push us toward an altered frame of mind. Like Boland and Lyytinen, they address questions of disciplinary core and identity, offering a rethinking to address the crisis of relevance we now face, thus turning a problem into an opportunity for renewal. They argue for reclaiming wider meanings of critique from the way the term commonly is understood in IS, either as its deployment in critical social theory or as in methodological critique. In exploring the connection between critique and crisis, they point out how critique can be a critical turning point. They advocate engendering crisis as way to move the field toward a holistic integration of research, teaching, and consulting.

Bell and Adam also are concerned with divisions, specifically that between ethics and IS. They see this as problematic both for education and practice. Ethics is taught (when it is taught) as separate from ISD. Both students and practitioners have trouble 
applying ethical codes or ISD methodologies to messy real-life situations. Bell and Adam find fault with rationalist rule-based decision models and the prominence of quantitative studies. Their discussion of ISD methodologies implicitly returns to IS education. Educators could use case studies that explicitly incorporate ethics into system development and rich descriptions of how ethical dilemmas actually are handled. They look forward to a body of qualitative research in this area as a useful resource for educators, transcending the limited view of ethical reasoning provided by quantitative research.

Purao and Truex also address the issue of practice and relevance, this time seen through another set of divergent paths in IS. They contrast software engineering's focus on creating information technology artifacts with research concerning organizational impact and change. In an attempt to remedy the lack of impact on the practice of research in either area, Purao and Truex combine insights from software engineering and social theories. They attempt to integrate the two streams by shifting from traditional development practices to a continuous redevelopment process. Drawing on emergent systems development, they propose a set of requirements for new representation techniques to take account of both the engineering of the IT artifact as well as the emergent nature of organizational context in which the IT artifact will be deployed. They call upon the WG 8.2 community to take up the challenge of reconciling these important and complex questions. They also sound a warning cry, that in having two research communities on parallel paths with little cross fertilization or mutual awareness, we miss the opportunity for great intellectual synergy and waste a great deal of creative energy in duplicated effort.

\subsection{Critical Interpretive Studies}

Papers in this section all consider different aspects of critical social theory (CST) in its relation to IS, both its use in our discipline or in more generic issues of interpretive methodology. CST is operationalized by anchoring it to various interpretive research traditions and techniques, or by positing linkages with other methods and theories.

The paper by Howcroft and Trauth considers the critical theoretic tradition in IS research by reflexively applying a critical lens to critical IS research. The authors find "little in the critical literature that differentiates critical IS research from other critical arenas." While avoiding issues of research technique, on the grounds that such questions "can detract from the more central problem of how we chose to interpret and represent social reality," they argue that a researcher should be concerned with a trio of tasks (namely, insight, critique, and transformative redefinition) when conducting critical IS research.

Greenhill's paper continues in a reflexive bent. It a self-conscious account of the process of conducting a detailed case study while employing thick description. The paper illustrates this with a description of the description and of the process. The author's goal was to contextualize the research by focusing on the method and the process of the research itself.

In a paper dealing with integrating CST and method, Cukier, Bauer, and Middleton offer an approach to operationalizing Habermas's validity claims in critical discourse 
analysis. They illustrate this in a technology-enabled learning case study, analyzing distortions of communication in the discourse of adoption and use of this system.

Klecun brings a new wrinkle to the growing endeavor to integrate actor-network theory with other social theories. Like Marcon, Chiasson, and Gopal, she looks outside the traditional writing on critical social theory, the perspective of the Frankfurt School. She makes a more difficult leap toward a critical postmodernism through the late work of Foucault, hinting at how to scope a research program using the related and relative strength of each approach.

The paper by Pozzebon responds to the invitation for authors in non-hermeneutic traditions of interpretivism to suggest other criteria for research quality than those made by Klein and Myers in their influential MIS Quarterly article. Pozzebon enriches the discourse on the critical interpretative perspective by exploring the link between interpretation and CST. She propounds four criteria for critical interpretative research: authenticity, plausibility, criticality, and reflexivity.

Focusing on interpretive work as a class (case research in particular), Barrett and Walsham address the basic question of the nature of a research contribution and then proceed to illustrate how IS research employing interpretive case studies can contribute to the advance of knowledge in our field. Their approach is interesting because they examine research contributions as statements in a network of ideas. Following Latour's second rule of method - that is, to examine the transformations of statements - they situate the particular case research findings within that network. Thus a contribution can be judged by its impact on the network and upon the types of transformations it undergoes as the network develops. They study the process of network construction via an examination of how others cite a familiar and well-cited interpretive case study. Barrett and Walsham's description of their own process represents an intriguing response to Lee's opening challenge. It embodies a sort of doubly reflexive approach to research in which the goal (i.e., the contribution) of the research is examined by reflecting on how that contribution has itselfbeen incorporated into the larger contextual network.

\subsection{Action Research}

Directly addressing the need for real-world relevance, action research has been postulated as the method for researchers to "rub" theory with practice. There has been an increase in its use in Europe and Australasia, but not significantly in North America and Asia. This has been due to different emphases on the nature of the main role of the researcher in the change process. One sees the academic as mainly acting as a social scientist in order to understand and explain practice. The other depicts the academic as a joint collaborator acting both as a researcher and also as a practitioner to improve practical outcomes in the organizational situation. In this section, the three papers explicitly or implicitly outline the role of the researcher, and attempt to answer some of the critiques of action research.

The first paper regards the researcher as a collaborator, with Oates reflecting on the move of social science from a linguist turn to an action turn. The author then defines a newer form of action research that places less emphasis on contribution to theoretical 
knowledge, and stresses participation and individual personal growth in organizations. This newer version of action research is then contrasted with more traditional forms in the literature. The paper presents a confessional account of a study and outlines five quality issues raised by this type of action research: relational praxis, reflexive-practical outcome, plurality of knowing, significant work, and new and enduring consequences or infrastructure. Because of the recent interest in action-based methods, the discussion about how to address these issues is important for the IS research community.

Germonprez and Mathiassen appreciate the researcher's role as a collaborator but want to bring more rigor associated with social science to the action-based research process. They explore the roles of conventional research methods that could contribute to the use of action research in multi-method approaches and the means by which they facilitate the creation of multi-contribution projects. The authors suggest and outline two approaches for the integration of action research. The first is a planned strategy where the main method is action research supplemented with other methods. The second is an emergent one in which more conventional methods are employed initially, and action research is then used to understand and explain the ongoing results that unfold in many projects. Finally, the authors argue that both combinations can decrease significantly the risk a researcher takes in using action research. If these approaches were adopted, action research would be more attractive for conventional IS researchers and doctoral students.

The final paper in this section, by Holwell, is based on work using Checkland's soft systems methodology for the UK National Health Service, with the academic again operating as a collaborator. This version of action research uses an intellectual framework of linked ideas through an intervention process applied to a situation. This process is a learning cycle, in which lessons can be generated about theory, method, and application. The author addresses the main criticisms leveled at action research: that it lacks both generalizability and also external validity from a single site and single focus study. The research program, described in three phases, covered a 4-year period, involved 20 organizations, and included 10 discrete, single action research interventions. Three concepts that are important in beginning to counter the main positivistic critics of action research that arise from these studies are recoverability, iteration, and themes.

\subsection{Theoretical Perspectives in IS Research}

The papers in this section are distinguished by a dominant concern with the use of theory in IS research, either by reviewing established practices or outlining a novel development of general significance to the field, by refining, integrating or even disinterring existing theoretical endeavor. A good starting point for synopsizing these contributions is the excellent panorama of the use of social theory in the WG's deliberations provided by Flynn and Gregory. Like Sawyer and Crowston, they look at past conference proceedings. In a remarkable effort of scholarship, all 381 papers in the 17 conferences since 1984 have been assayed. The prevalence of empirical social theory in this collective oeuvre apparently runs at 46 percent, with 175 papers manifesting a significant interest in theory either as an analytic device or the object of validation and development. There are oscillations over the period, but a trend toward greater promi- 
nence of social theory can be descried. Other highlights are the steadily increasing use of qualitative and interpretive methods, together with some fascinating research demographics, such as the proclivity of male researchers, especially in North America, to adopt the positivist paradigm.

Intriguingly, Flynn and Gregory draw up a "hit parade" of the top 10 social theories in WG 8.2 research. Actor-network theory (ANT), perhaps unsurprisingly, comes out as number 1 , followed closely by structuration theory. Despite this, we are clearly a cosmopolitan community, with the top 10 accounting for less that 20 percent of the papers sampled. Interestingly, CST is not as prominent in the list as might have been expected, although Foucault comes in at number 3. The clutch of papers in this section, and in the conference more generally, is consistent with its forebears. Both ANT and structuration theory figure prominently in the section, with two of the papers attempting in different ways to conjoin the two perspectives.

Brooks and Atkinson propose a proprietary synthesis which they dub StructurANTion. The neologism symbolizes the complementarity seen by the authors. Whereas structuration theory provides an account of the interactive dynamics whereby social structures are held together (through the recursive enactment of socially constructed rules) and thus emphasizes stability, ANT provides a complementary narrative addressing the dialectics of socio-technical transformation in terms of the reconfiguration of networks of human and nonhuman actants. Brooks and Atkinson's framework is intended to be a practical as well as an ornamental edifice, and they illustrate its deployment in an action research project in the UK National Health Service focused on the development of patient-oriented services for cancer care.

Rose, Lindgren, and Henfridsson are also concerned with theoretical unification, again involving ANT and structuration theory. Their primary concern is fundamental for our discipline, namely whether we are to be eternally condemned as the users (and abusers?) of theory from elsewhere, rather than the builders of theory in our own right. The authors propose the idea of "adaptive theory making" as a distinctive role for applied disciplines such as IS. Our concern with practical intervention inevitably enjoins a degree of healthy pragmatism in which we draw on the most appropriate theory available from a diverse array of sources, and assemble it into a multifaceted whole. The concept of structure is taken as an example, and an attempt made to integrate elements from three theoretical discourses: structuration theory, ANT, and Chomsky's linguistic work on deep versus surface structure. A case study is used to illustrate the approach in action, this time in the manufacturing domain (Volvo's attempt to design a competence management system).

ANT figures for a third time in the paper by Wagner, Galliers, and Scott. Here the aim is methodological development regarding the deployment of ANT. The authors propose the use of narrative methods for conducting interviews with human actants in ANT studies. In these interviews, the researcher focuses on the meanings and explanations given by participants to the unfolding events in IT-enabled organizational change. They contend that there is a natural sympathy between ANT and the narrative approach. Again, a case study is presented for illustrative purposes. It describes the vicissitudes of an enterprise research planning implementation in a university setting, in which the use of the best practice ideal as a means of translating interests in support of the project was only partially successful, with significant concessions ultimately being forced in terms of local customs and traditional practices. 
Activity theory is the subject of the paper by Korpela et al. Although on Flynn and Gregory's hit parade (at number 6), the authors argue that, since its first appearance at the Copenhagen conference in 1991, activity theory has received little attention within IS, despite being influential in cognate fields (such as computer-supported collaborative work) and having an impressive intellectual pedigree stretching back 80 years. The authors pose the somewhat rhetorical question of whether this is a "dead horse" worth flogging, or a paradigm deserving of renewed attention. They clearly believe the latter, arguing that certain features of activity theory make it particularly suited for a key role in IS research and development, such as its focus on work systems and its concern with worker emancipation. In order to promulgate its greater use, they argue that a practical development methodology is necessary, embodying activity theory concepts and principles. Such a framework is described (ActAD) and an illustrative case study set in a perinatal intensive care unit is provided.

The work of Orlikowski also features in the top 10, at number 5 in the Gregory and Flynn list of favorites. It is the subject of the next of our papers, by Davidson and Pau, who see unfulfilled potential in Orlikowski's work with Gash on technological frames of reference (TFM). Despite many citations, little real use of TFM in IS research practice has transpired. After tracing the genealogy of TFM, eight studies involving its use are analyzed, from which a number of potential refinements and possible enhancements are delineated. Some of these are substantive (e.g., developing a set of generic frame attributes, moving beyond a limited concern with frame incongruence as the source of change resistance); others are methodological (e.g., the deployment of TFM in an action research mode to enhance its relevance to practice and its fertility as a source of new IS theory).

The last of the papers in this section marks a departure by introducing theoretical ideas that are relatively new in our domain. Although social theory in general has been widely used in the 8.2 community, it is arguable that psychological theory has been neglected, reflecting our general preoccupation with social and organizational issues rather than those at the individual level. Adams and Avison draw on an eclectic mix of psychological theory that deals with cognitive blocks and biases, and how these are influenced and reinforced by the technical characteristics of development tools and methods. These are serious concerns, as the adoption of a particular methodology will inevitably have a decisive bearing on the conduct of the design process and the lineaments of the resulting IS artefact. The paper makes a useful contribution by providing a theoretical framework in which to understand these biases and the possible malignant effects they may have.

\subsection{Systems Development: Methods, Politics, and Users}

This section addresses the theory/practice relationship and disciplinary concerns from another standpoint, that of systems development. IS has been recognized as a discipline for more than 30 years. During that time it has rapidly evolved to reflect changes in the application of information and communication technologies to a variety of situations. Today, information systems development still remains one of the major areas for enabling IS researchers to understand how theories can be applied to complex 
practice. In this section, seven papers raise issues and challenge our assumptions about the systems development process itself, methods in use, political aspects, and users' participation and behavior.

Tan, Lim, Pan, and Chan analyze two in-depth case studies of a governmental institution and a commercial establishment using Montealegre's process model of capability to explore how enterprise system adoption can be strategized for the purpose of dynamic capability development. In doing this, the authors develop a process model for enterprise system adoption that captures the essence of the interdependencies between enterprise systems and dynamic capability development. They conclude that enterprise systems can be strategic partners in the capability development process in organizations.

Lings and Lundell discuss the difficulties of transferring a research method into a commercial context. They argue that method transfer is a special case of knowledge transfer. Based on four case studies of method transfer, a framework is postulated with implications for method development. Four main themes in the framework are the importance of a clear conceptual framework for a method, support for learning, usability within a defined context, and acceptability to stakeholders.

The next two papers take up the challenge of integrating critical social theory with practice. In the first, an action research project by Waring provides an opportunity to engage in a critical approach to systems analysis with the intention of exploring the politics of organizational life through the medium of integrated information systems projects in the UK National Health Service. The paper describes how the emancipatory principles of Habermas can be used to develop an innovative approach to participative process and information flow modeling. One of the conclusions is that complex social, organizational, and political issues endemic within organizations inhibit true discourse and therefore constitute a barrier to effective ICT introduction and the integration of information systems.

In the following paper, Tapia argues that a critical orientation is necessary to understand ICT-enabled workplace culture and employee behavior. This study is based in a dot-com organization where a group was resistant to organizational authority as the result of comparable companies beginning to close. The paper shows that ICT-based innovation may lead to increased deviant or resistant behavior in staff. Furthermore, it concludes that the social environment of the dot-com bubble has allowed several myths to propagate and affect human behavior in similar organizations.

The paper by Puri and Sahay picks up on the themes of participation and power. Puri and Sahay concentrate on how to understand the knowledge politics in using and designing a geographical information system (GIS) for land management in an Indian context. They argue that power and politics are inseparable from the systems development process and also that knowledge of the local context can complement scientific knowledge that is needed to develop and use the GIS. The link between participation and knowledge for meaningful use of GIS is crucial and communicative action can lead to better design and technology acceptance by end-users.

User participation in developing information systems also is addressed by Aanestad, Henriksen, and Pors. This has always been an important area for the 8.2 community. This paper discusses three user-led projects that utilize generic technologies. These developments were not formal processes but involved users significantly in influencing 
the direction and outcome of the projects. The importance of continuing redesign, tailoring, and adaptation when using these technologies is learned from these cases.

Finally in this section, Bansler and Havn give an account of improvisation in action as an attempt to make sense of information systems development in organizations. They report a longitudinal field study of the development of a Web-based groupware application in a multinational corporation. In analyzing the dynamics of this situated process, they argue that improvisation and bricolage play a vital role in the development of the project. In conclusion, they suggest that this case provides an opportunity to reconceptualize IS development.

\subsection{Panels and Position Papers}

The panels and position papers unsurprisingly echo many of the themes and motifs of the full research papers.

Issues regarding research method preoccupy two of the panels. The first, "Twenty Years of Applying Grounded Theory in Information Systems," discusses the promise grounded theory holds for our field and its wide use as a method for generating IS theory from qualitative data. The panel addresses a set of concerns, including its problematc relationship with positivism and the all-too-common lack of rigor in its deployment, often to endow spurious legitimacy on any form of coding or indeed informal content analysis. Action research (section 4) is the subject of the panel entitled "Building Capacity for E-Government: Contradictions and Synergies in the Dialectics of Action Research." The promise of action research as a tool for building relevant IS theory is directly addressed by this panel, with the spotlight thrown on the tensions that this creates in the research process as the imperative to solve a practical organizational problem conflicts with the requirement to deliver results of general theoretical interest to the wider research community.

Theoretical matters are addressed by two of the panels, picking up and developing some of the themes intoned in section 5. The nature of agency in socio-technical systems is tackled by the panel on "New Insights into Studying Agency and Information Technology" Is agency an exclusively human attribute, is it primarily a technological capability, or is it an inseparable property of the interaction of the two? Several of the theoretical perspectives featured in the full papers are drawn into the debate, with structuration theory, ANT and critical theory all making an appearance. The potential of activity theory as a theoretical substrate underpinning a critical approach to IS practice is addressed by the panel on "Researching and Developing Work Activities in Information Systems: Experiences and the Way Forward." This panel carries forward the general arguments for a participative, work-oriented approach to ISD laid out in the full research paper coauthored by several of the panelists (Korpela et al.). The focus of the panel is on developing methodological guidelines for implementing the proposed approach.

The two remaining panels address issues facing the conference on a more general front. The panel "Crossing Disciplinary Boundaries: Reflections on Information Systems Research in Health Care and the State of Information Systems" asks, in a wideranging way, to what extent the aspirations of relevant research have been realized in the 
domain of health care. The commonalities, and differences, in the experience of researchers in the medical informatics community and in our own field are addressed. The differential treatment of ethics in the two areas might be highlighted given the relative neglect of this topic in our field, as Bell and Adam lament (see section 2). In general, the flow of knowledge and experience could be in either direction, with the medical informatics and IS communities learning from each other's travails. The last and only invited panel, "The Great Quantitative/Qualitative Debate: The Past, Present, and Future of Positivism and Post-Positivism in Information Systems," provides a more panoramic and dialectical discussion of IS methodology. This panel addresses many of the core issues debated within the conference, which have been leitmotifs of the larger methodological discourse over the last two decades. As a microcosm of the conference itself, the panel will review progress in terms of two key deliberations: the opposition between quantitative and qualitative research methods and the ascendancy of postpositivistic approaches (critical and interpretive). The modernist notion of progress will itself be debated, and a plea entered for greater diversity and pluralism in our research practice, an injunction of earlier methods conferences echoed in several submissions presented here.

Turning finally to the position papers, a number of resonances are notable, with the papers falling into three distinctive clusters, mirroring the structure of the main program Unsurprisingly, research methodology preoccupies many of these short pieces. The inherent tensions in action research are trenchantly pointed up by Breu, Hemingway, and Peppard. An illustration is given showing how the unequal exercise of power on behalf of the practitioner "side" severely compromised the rigor of the research interest in an industrially based project. The relationships between critical research and both positivism and interpretivism are addressed by Wilson and Greenhill, who add their voice to the general call for methodological pluralism. Of note in their stance is the adoption of a realist ontology to complement their overall concern with emancipation. The limits of positivism and the poverty of scientism are the subject of Jain's polemic. His philippic is based on a rejection of Cartesian dualism and an advocacy of non-dualist positions, drawing on the philosophies of Kant, Hegel, Heidegger, and Zen. Bednar's paper also addresses method, though here the primary concern is with IS development rather than research. The analysis of contextual dependencies, within a double-loop sense-making process, is proposed as a tool for addressing gender-related issues, at both the micro and macro levels, within the systems development process.

Foundational issues come to the fore in the second group of position papers. Ethical concerns resurface in the paper by Stolterman and Fors, whose main thesis challenges us to reflect critically on core issues at the heart of our discipline by asking questions regarding the purpose of IS development and research, as well as issues of methodology and ontology. They call for improving the quality of life (the idea of the "good life") as a design aim, echoing the ideological stance of extant IS methodologies such as sociotechnical systems design. Foundational issues also are addressed by Stephens, who challenges the often uncritical definition of the concept of information adopted within the IS field and cognate domains. He considers it vital that this concept is reproblematized, and a broader view taken of information as a "complex phenomena embracing such issues as propriety, regulation, ethics, accessibility, and even aesthetics." Like Introna and Whittaker (section 2), Webb also visits the problematic nature of truth 
and its relationship to the academic publication process. Webb, in an interesting comparison of a conference and a journal report of the same study, finds different truth standards applied to inductive and deductive generalizations.

The final clutch of position papers addresses aspects of theory and its deployment in IS research. The methodological enhancement of ANT is the concern of Pouloudi, Gandecha, Atkinson, and Papazafeiropoulou, just as it is in the full paper by Wagner et al. (section 5). Here stakeholder analysis is advocated as a tool for identifying actants within an overall analytical approach based on ANT. The paper by Ng and Tan is also of interest from a theoretical and methodological perspective. It deploys an interesting admixture of ethnography and symbolic interactionism in an intriguing analysis of users' adherence to in-house, legacy systems in the face of an ERP implementation. The use of symbolic interactionism is of particular interest as this theoretical lens has prima facie much to offer to IS research, although arguably underutilized to date. Further theoretical novelty is provided by Whyte, who draws on work in the innovation studies tradition to develop a new theoretical lens for analyzing the IT artifact that draws together both a supply and a use side perspective. Whyte argues that these viewpoints traditionally have been kept separate in our field. A case study of virtual reality technology is provided to demonstrate the new lens in action. The rapid development of information technology, outstripping the pace at which we can understand its meaning and effects, is Olsson and Russo's concern. They are interested in so-called "nomadic information systems," and provide a case study of a context-aware exemplar of this relatively new technology (CABdriver) to illustrate the effectiveness of adaptive structuration theory as an analytic lens to examine its impact.

\section{CONCLUDING REFLECTIONS}

In putting together our final thoughts for this twentieth anniversary of the Manchester Conference, we asked the past chairs of the Working Group, and of the previous three methods conferences, to reflect on the Group's influence and significance in the various methodological turns taken by the IS community in the past 20 years or so. We are very grateful for their whole-hearted cooperation in this retrospection. Their remarks were remarkably similar. All pointed to the stimulation and enjoyment provided by participation in the Group's work, to the pleasure of finding a collection of people who took ideas seriously, self-critically challenging themselves to find new ways of thinking. This has been a hallmark of the Working Group throughout its history, turning our gatherings, according to one chair, into life-changing inspirational events. The past chairs reminisced with pride about the growth of WG 8.2 to be the largest IFIP working group. All were proud of our role in making qualitative methods a respected part of IS research and relished the coming together of varied but kindred spirits within our community as both fun and intellectually stimulating. All encouraged us to "stick at it," to keep our thinking fresh and our meetings provocative.

All agree that the 1984 Manchester conference had thrown down a gauntlet and challenged the traditionalist orthodoxy with approaches that were not common at that time in the discipline. The conference had challenged the scientific method in information systems research and called for greater pluralism and diversity. Its success was 
marked by the growing legitimacy of the linguistic and qualitative turns in IS research. As WG 8.2 grew and asserted itself, held meetings in conjunction with the International Conference on Information Systems, and nurtured researchers who began publishing in, and later joining editorial boards of, respected journals, what we originally thought of as "methods wars" were over, and the battle won. Victory was effectively proclaimed at the 1997 conference and journals such as MIS Quarterly claim to have left such concerns behind.

But is the war over? Can we now rest on our laurels? Have not the tyros of 1984 become the old guard of today; no longer rebels laying siege to the bastions of research conservatism, have they now become gatekeepers, sometimes seeming to police the very methods they helped establish as legitimate? Will we continue to see more flowers blooming and intellectual diversity flourishing, or are storm clouds brewing? Is history really at an end? The papers in this volume suggest not, that there is indeed much unfinished business. While not generally addressing the qualitative-quantitative debate, the present collection of papers reflect remarkably similar concerns to those exercising the 1984 gathering: a sense of crisis in IS, concern over the relevance/rigor and research/practice splits, debate over the role of theory, challenges to the very legitimacy of IS as a discipline. Can the methods wars be over while these issues persist?

With such questions in mind, and with the encouragement from the past chairs and authors in this collection, we offer further challenges to our community based on our observations of the contributions to this conference. The papers offer an exciting mix of ideas and combinations of theories, continuing the WG 8.2 traditions both of critical reflection and methodological eclecticism. We are delighted that the reviewers and associate editors kept to the Group's tradition by turning a critical eye on the papers, treating nothing and no one as a sacred cow. Everyone, the highly regarded as well as the newcomers, benefitted from their scrutiny and thoughtfulness. Not one paper made it through the review process unscathed. All were asked to revise, and many revised more than once, so papers became better and better. The reviewers proved themselves critical in the best senses of the word and in the best traditions of WG 8.2, and we, the program chairs, tried to do the same. In the interest of seeing more diversity in thought and approach, we occasionally overrode reviewers' decisions when we thought a paper had something particularly interesting to say, and decided to give the author(s) another chance to say it better. Some of those turned out to be excellent thoughtful papers, to challenge us to think, and then think some more. We also decided to try a new idea which eventually developed into a forum for the "bright ideas" or position papers. This innovation, we hope, will further stimulate radical thought and add to the spirit of debate.

We have taken to heart the past chairs' admonitions not simply to congratulate ourselves on the successes of the Group, but to continue to pioneer new ideas. In the spirit of pushing our community further forward, we note some potentially problematic tendencies in the papers in this volume. One is a continuing confusion over, and sometimes conflation of, IS development method and IS research method. These are distinctive problem domains, and clear differentiation is required. Whereas the objective of the former is to design and deploy working artifacts through the use of information systems development methods, the prerogative of the latter is the production of IS theory through appropriate research techniques. Methods for designing and building systems 
(e.g., structured methods, soft systems) are not the same as methods for developing social theory (e.g., the hypothetico-deductive process of normal science, grounded theory, etc.). This conference covers both dimensions of method, but in clearly demarcated categories.

We have also attuned ourselves to the general sense of defensiveness that sometimes seems to imbue our field, that we need to guard ourselves against encroachment or imperialism from other, less-diffident disciplines. The conference papers reflect two sets of possibly contradictory threads marking current discussion and controversy within IS resulting from this. Perhaps in the spirit of "attack being the best form of defense" or the theory of preemptive strikes, one thread calls for IS to be a reference discipline for other fields (i.e., to be imperialistic itself). This thread is as apparent in this volume as it perhaps has been in earlier times. The other is a persistent feeling that we must bring in theory from outside, especially from esoteric French and German social theorists and philosophers. We note a continuing dilettante tendency in the conference papers to borrow theory from Latour, Habermas, Foucault, and assorted others. We have nothing against French and German theory, but why these individuals in particular? Are there no other social theorists or philosophers worthy of attention? Is this interest promoted by the siren allure of the obscure and the exotic? Of course, there are examples outside this clique in the erudition mustered here, but perhaps not the degree of diversity suggestive of a healthy, open spirit of inquiry and scholarship. The list is more notable in that few French and Germans even participate in WG 8.2, much as we wish they would.

A number of papers propose novel combinations of these and other theories, creating "new" theory through something like hybridization. Indeed, we half-jokingly entitled a conference session "ANT-plus" at one point in our deliberations. As with any hybrids, we wait to see which will be robust examples of hybrid vigor. But hybrids are variations on their parents. We would like to see more of our own theory developed in addition to borrowing from others. Must theory come from outside to be acceptable? One way a corpus of home-grown theory might be cultivated is through grounded theory. Although we applaud using qualitative approaches for theory generation, we are concerned that grounded theory is sometimes written about as a theory, rather than as a method for generating for theory. Moreover, there seems to be a tendency to conflate grounded theory with qualitative research; labeling what one does as grounded theory seems to serve the purpose of legitimating it, when a less grandiose appellation (such as inductive reflection) may actually be more accurate. Similar concerns are taken up by one of the panels. We hope our observations will prevent co-optation of qualitative approaches into some increasingly innocuous, and therefore acceptable, form.

We point to a rather different concern when we examine the make-up of IFIP Working Group 8.2. Just as a plurality of methods and theories enlivens the field and leads to increased understanding, so would a good mix of people along a variety of dimensions. For example, there have been relatively few participants outside the United States, the United Kingdom and her former colonies, and northern Europe in general. Alas, the same is true for this conference. While we clearly see the contribution, for instance, that the Scandinavian social democratic tradition has made to both theory and practice in our field, would that other perspectives were brought into the fold from different political and social backgrounds removed from those with which we have 
become so comfortable. We would like to see further enrichment deriving from consideration of a broader range of working contexts than those of the business world, and we are gratified to see papers in this volume based on experiences in hospital, governmental, and educational settings. We hope WG 8.2 becomes an even more welcoming place for participation from those studying IT in settings outside business organizations. Similarly, although we tend to draw on ideas from a variety of other disciplines, we infrequently work with people in those disciplines or invite them to our conferences. As one past chair remarked, when we have expanded our horizons by inviting "outsiders," we changed the networks and dynamics of the Working Group. Here's to making more outsiders insiders, or at least welcomed guests.

We also note a tendency toward introspection. We applaud self-reflection. As is evident in this chapter, we are certainly guilty of it ourselves. But we also need to be wary. At what point does legitimate concern with methodology, or the state of the discipline, become an immobilizing obsession? Is debate about methodology a displacement activity that removes and detaches us from genuine but daunting engagement with the world of practice that we purport to influence? Perhaps we had best get on with our work, doing our research as best we can, sans such posturing over theory and method. But that, too, is part of what WG 8.2 is about. We invite all to join in the fun and fray of this anniversary celebration and, through this conference and the future work we hope it stimulates, continue the tradition of keeping our meetings and our field, fresh, vigorous, and provocative.

\section{ABOUT THE AUTHORS}

Bonnie Kaplan is on the faculty of Yale University's School of Medicine and is a faculty affiliate of the Information Society Project at the Yale Law School, and a Senior Scientist at Boston University's Medical Information Systems Unit. She previously held faculty appointments in Information Systems. She specializes in change management, benefits realization, and people's reactions to new technologies in health care. She consults for academic, governmental, private, and business organizations in health care. Her publications have appeared in such journals as Methods of Information in Medicine, Journal of the American Medical Informatics Association, International Journal of Medical Informatics, Artificial Intelligence in Medicine; Science, Technology and Human Values, and MIS Quarterly. She chairs the International Medical Informatics Association Working Group-13: Organizational and Social Issues, and chairs the Yale University Interdisciplinary Bioethics Project Research Working Group on Technology and Ethics. She is a recipient of the American Medical Informatics Association President's Award and a Fellow of the American College of Medical Informatics.

Duane Truex researches the social impacts of information systems and emergent ISD. He is an associate editor for the Information Systems Journal, has coedited two special issues of The Database for Advances in Information Systems, and is on the editorial board of the Scandinavian Journal of Information Systems, the Journal of Communication, Information Technology \& Work, and the Online Journal of International Case Analysis. His work has been published in Communications of the ACM, Accounting Management and Information Technologies, The Database for Advances in Information Systems, European Journal of Information Systems, le journal de la Societé d'Information et Management, Information Systems Journal, Journal of Arts Management and Law, IEEE Transactions on Engineering Management, and 40 assorted IFIP transactions, edited books, and conference proceedings. He is a member of the Decision Sciences and Information Systems faculty in the Chapman Graduate School, College of Business, at Florida 
International University, and is an associate professor on leave from the Computer Information Systems Department, Robinson College of Business, at Georgia State University.

David Wastell is Professor of the Information Society in the School of Informatics at the University of Manchester. His current interests are in business process re-engineering, electronic governance, IS research methods and the human factors design of complex systems. He has published around 100 journal articles and conference papers in Information Systems, human factors, health informatics and research methods, after an early research career in cognitive and clinical psychophysiology. He is on the editorial board of European Journal of Information Systems and Information and Management, has co-organized one previous IFIP conference (WG 8.6), and has co-authored two previous edited collections. He has considerable consultancy experience, especially in the public sector.

Trevor Wood-Harper is Professor of Information Systems at the School of Informatics at the University of Manchester and is Professor of Management Information Systems at the University of South Australia, Adelaide. Trevor has held visiting chairs at University of Oslo, Copenhagen Business School, and Georgia State University. He has coauthored or coedited 16 books and proceedings and over 200 research articles in a wide range of topics including the Multiview Methodology, information systems evolution for developing countries, electronic government, action research, ethical considerations in systems development, fundamentals of information systems and doctoral education. He has successfully supervised 25 doctoral students and acted as an external examiner for more than $75 \mathrm{Ph} . \mathrm{D}$. theses in the UK, South Africa, Norway, Sweden, and Australia. 